\title{
Synthesis of Polypeptide by Phosphorylation of $\alpha$-Amino Acid Salts
}

\author{
Naoya Ogata, Hozumi Tanaka, and Kazutoyo Uno \\ Department of Chemistry, Sophia University, \\ 7 Kioi-cho, Chiyoda-ku, Tokyo 102, Japan.
}

(Received June 23, 1975)

\begin{abstract}
KEY WORDS Polypeptide / $\alpha$-Amino Acid / Polycondensation / Phosphorylation / Triaryl Phosphite / Imidazole /
\end{abstract}

As is well known, there are many routes to the synthesis of polypeptides which have been developed by a stepwise polymerization of $\alpha$-amino acid derivatives, including $N$-carboxyanhydride or active esters of $\alpha$-amino acids. Direct polycondensation of $\alpha$-amino acids has been reported by Yamazaki, ${ }^{1}$ in which several $\alpha$-amino acids were subjected to polycondensation to yield polypeptides by usiug triaryl phosphite and pyridine as initiators. On the other hand, we have reported in previous papers ${ }^{2-4}$ that nylon salts from dicarboxylic acids and diamines were easily subjected to a polycondensation reaction to produce polyamide in the presence of triaryl phosphite and imidazole under mild conditions.

However, when the phosphorylation reaction using triaryl phosphite and imidazole was applied to the polycondensation of $\alpha$-amino acids, only a dimerization reaction of the two amino acids having protective groups could occur; no polypeptide was obtained by the direct polycondensation of $\alpha$-amino acids. ${ }^{2,5}$ Recently, it was found that polypeptide was obtained in a good yield by the phosphorylation reaction, when an acid salt of $\alpha$-amino acids was used instead of free $\alpha$-amino acids. This paper deals with the synthesis of polypeptide from $\alpha$-amino acids salts by the phosphorylation with triaryl phosphite and imidazole under mild conditions.

$\alpha$-Amino acid salts prepared from $\alpha$-amino acids and mineral acids were suspended in various solvents with a vigorous stirring in the presence of given amounts of triaryl phosphite and imidazole. The suspension of $\alpha$-amino acid salts gradually transformed into a gel swollen by solvents. After a given period, the gel solution was poured into excess acetone and the precipitated polymer was filtered, followed by washing with water and drying. Solution viscosities of the polymers were measured in dichloroacetic acid $(0.5 \mathrm{~g} / \mathrm{d} l)$ at $30^{\circ} \mathrm{C}$.

Table I presents the results of the polycondensation of various salts of glycine in dimethylacetamide (DMAc) solution. Identification of the polymers from their glycine salts was carried out by infrared and elemental analyses, which also supported the existence of the polyglycine structure. The sulfuric acid salt of glycine transformed into polyglycine in almost quantitative yield, although the solution viscosity of the resulting polyglycine was not so high.

Table II summarizes the results of the polycondensation of the hydrochloric acid salt of glycine in various solvents at room temperature. It is seen that amide solvents such as dimethylformamide (DMF) or DMAc were favorable for

Table I. Polycondensation of glycine salts by phosphorylation in DMAc at room temperature ${ }^{a}$

\begin{tabular}{lccc}
\hline \multirow{2}{*}{ Glycine salt } & Time, hr & \multicolumn{2}{c}{ Polymer } \\
\cline { 3 - 4 } & & Yield, \% & $\eta_{\text {inh }}$ \\
\hline $\mathrm{H}_{2} \mathrm{SO}_{4}$ & 50 & 93 & 0.15 \\
$\mathrm{HCl}$ & 24 & 48 & 0.08 \\
$\mathrm{CH}_{3} \mathrm{COOH}$ & 48 & 43 & 0.09 \\
$\mathrm{CH}_{3} \mathrm{C}_{6} \mathrm{H}_{4} \mathrm{SO}_{3} \mathrm{H}$ & 24 & 43 & 0.08 \\
$\mathrm{AlCl}_{3}$ & 48 & 14 & - \\
\hline
\end{tabular}

a Monomer concn, $0.5 \mathrm{~mol} / l$; imidazole, $1 \mathrm{~mol} / \mathrm{l}$; triphenyl phosphite, $0.5 \mathrm{~mol} / \mathrm{l}$. 
Table II. Polycondensation of glycine hydrochloride in various solvents at room temperature ${ }^{a}$

\begin{tabular}{lcccc}
\hline \multirow{2}{*}{ Solvent } & Time, & \multicolumn{2}{c}{ Polymer } \\
\cline { 3 - 5 } & hr & $\begin{array}{c}\text { Yield, } \\
\%\end{array}$ & $\eta_{\text {inh }}$ \\
\hline Dimethylformamide & 24 & 49 & 0.08 \\
Dimethylacetamide & 24 & 48 & 0.08 \\
$N$-Methyl- $\alpha$-pyrrolidone & 24 & 44 & 0.08 \\
Pyridine & 24 & 13 & - \\
Tetrahydrofuran & 24 & 10 & - \\
Dioxane & 25 & 4 & - \\
Nitrobenzene & 25 & Trace & - \\
Dimethylsulfoxide & 25 & 0 & - \\
Hexamethylphosphotriamide & 24 & 0 & - \\
$m$-Cresol & 24 & 0 & - \\
Benzene & 24 & 0 & - \\
Ethanol & 24 & 0 & - \\
Acetonitrile & 24 & 0 & - \\
\hline
\end{tabular}

a Monomer concn, $0.5 \mathrm{~mol} / l$; imidazole, $1 \mathrm{~mol} / l$; triphenyl phosphite, $0.5 \mathrm{~mol} / l$.

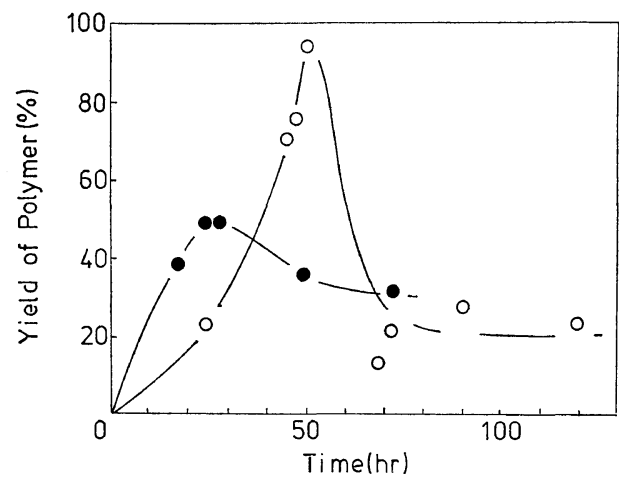

Figure 1. Polycondensation of glycine salts by phosphorylation: (O) $\mathrm{HCl}$ salt; (O) $\mathrm{H}_{2} \mathrm{SO}_{4}$ salt; monomer concn, $0.5 \mathrm{~mol} / l$; imidazole, $1 \mathrm{~mol} / l$; triphenyl phosphite, $0.5 \mathrm{~mol} / l$; room temperature.

polymer yields. Figure 1 indicates the polycondensation behaviors of the sulfuric or hydrochloric acids salts of glycine in DMAc solution in terms of the polymer yields. The polymer yields reached maximum after a certain period. Temperatures higher than $60^{\circ} \mathrm{C}$ also caused a decrease in polymer yields and in solution
Table III. Polycondensation of various $\alpha$-amino acid salts in DMAc at room temperature

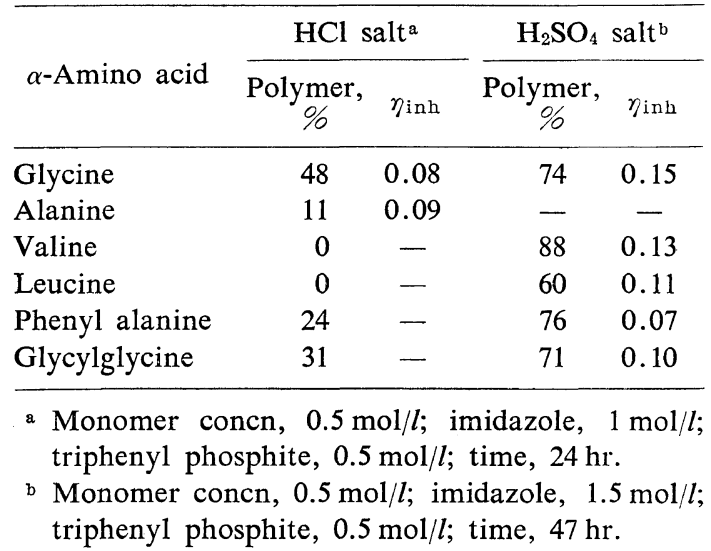

viscosities.

Table III indicates the results of the polycondensation of various acid salts of $\alpha$-amino acids by the phosphorylation reaction. It is seen in Table III that the yields of polypeptide depended on the kind of salt; generally speaking, sulfuric acid salts are seen to be superior to hydrochloric acid salts with respect to polymer yields. This dependence on the salt type might be related to the dissociation of the ammonium group of the $\alpha$-amino acid salt.

The reaction mechanism of the $\alpha$-amino acid salts by the phosphorylation reaction will be discussed in a later paper. A tentative explanation is that the amino group is protected by the salt formation and an exclusive phosphorylation of the carboxyl group of the $\alpha$-amino acid might occur, resulting in an easier formation of polypeptide.

\section{REFERENCES}

1. N. Yamazaki, F. Higashi, and J. Kawabata, J. Polym. Sci., Polym. Chem. Ed., 12, 2149 (1974).

2. N. Ogata and H. Tanaka, Polymer J., 2672 (1971).

3. N. Ogata and H. Tanaka, ibid., 3, 365 (1973).

4. N. Ogata and H. Tanaka, ibid., 6, 461 (1974).

5. Yu. V. Mitin, et al., Tetrahedron Lett., 5267 (1969). 